\title{
Pontes imaginárias sob o céu da manguetown: o mangue beat e os novos olhares sobre o Recife $^{1}$
}

\section{David Tavares Barbosa² \& Caio Augusto Amorim Maciel ${ }^{3}$}

\author{
${ }^{2}$ Mestrando em Geografia - PPGEO/UFPE.E-mail: davidtbarbosa@hotmail.com \\ ${ }^{3}$ Prof. Dr. do Departamento de Geografia - UFPE.E-mail: caio.maciel@pq.cnpq.br
}

Recebido em 04/2012. Aceito para publicação em 12/2012.

Versão online publicada em 01/02/2013 (http://seer.ufrgs.br/paraonde)

\begin{abstract}
Resumo: A questão principal deste trabalho consiste em analisar o movimento Mangue Beat, buscando compreender como os discursos desta cena cultural contribuiram para uma reconstrução e/ou remodelação das paisagens da cidade do Recife, através da criação de novos signos para a urbe e seus espaços públicos. 0 projeto foi desenvolvido mediante pesquisas iconográficas na produção cultural do Mangue Beat, somado à revisão da literatura acerca da problemática sócio-espacial do Recife e observações técnicas no espaço urbano da cidade. Buscar-se-á apontar nos resultados que a crítica da cidade elaborada pela cena mangue a partir de contribuições diversas, pretendeu ser mais abrangente e integrativa (o estuário ligando todos os pontos e todas as frações de classe da Manguetown, em ebulição e potencialmente em revolta) do que as propostas de transformações urbanas desenvolvidas pela prefeitura, posterior ao debate crítico promovido pelo referido movimento.
\end{abstract}

Palavras-Chave: Recife. Mangue Beat. Rio Capibaribe. Paisagens.

\section{Introdução}

Muito se tem debatido acerca da validade dos estudos de expressões artísticas, como o cinema, a música e a literatura a partir de uma perspectiva geográfica. Questões culturais tornam-se cada vez mais emergentes nos debates mundiais, na medida em que a mundialização da cultura, a dissolução das fronteiras, os choques culturais e a interpenetração de culturas são intensificadas pelo mundo. Se a emergência de situações globais revela a necessidade de valorização da variável cultural no estudo geográfico, na escala local, mais especificamente para este artigo, nas cidades, estes estudos são extremamente necessários.

Dentro do contexto de cidades cada vez mais cosmopolitas e multiculturais, analisar o Mangue Beat, assim como outras inúmeras expressões culturais, numa perspectiva espacial da cultura torna-se condizente, visto ser este movimento desenvolvido em relação direta com o espaço da cidade do Recife, criando novos signos para a cida- de, e reivindicando, por meio da política - do discurso e da ação - a elucidação de problemas sociais e ambientais do Recife, lançando novos debates sobre os ambientes do rio Capibaribe.

Torna-se então relevante desenvolver este estudo, pois parte-se da consideração de que devemos avançar nos estudos sobre as cidades além das aperências de suas materialidades, pois importantes aspectos sociais se processam nestes espaços além das realidades concretas, sendo a cidade também construída através das práticas cotidianas de seus habitantes, através de suas atividades mentais, emocionais e afetivas, que variam segundo a posição social destes atores sociais.

As obras iconográficas analisadas neste artigo referem-se à produção artística realizada por duas bandas que integraram o Mangue Beat: Chico Science \& Nação Zumbi e Mundo Livre S/A. Para isto, foram selecionados os seguintes álbuns: Da Lama ao Caos (1994) e Afrociberdelia (1996), da Chico Science \& Nação Zumbi; Samba Esquema Noise (1994); Guentando a Ôia (1996); Carnaval na

${ }^{1}$ Pesquisa realizada junto ao PIBIC/CNPq/UFPE sob o título "Entre discursos e ações: Influências do Mangue Beat sobre as políticas públicas acerca do rio Capibaribe". Apresentada como trabalho de conclusão de curso em Bacharelado em Geografia na UFPE com o título "Pontes Imaginárias sob o céu da Manguetown: Influências do Mangue Beat sobre as políticas públicas no entorno do Rio Capibaribe - Uma análise do Circuito da Poesia e do Carnaval Multicultural". 
Obra (1998), da Mundo Livre S/A. Procurou-se identificar, mapear e caracterizar os geossímbolos mobilizados pelo Mangue Beat no meio urbano recifense, segundo a sugestão metodológica de Maciel (2005) para a interpretação de metonímias geográficas a partir da retórica da paisagem.

Parte-se assim do pressuposto de que as músicas do Mangue Beat, assim como os discursos e falas de seus integrantes, apresentam significados simbólicos inerentes a toda e qualquer ação humana de construção dos espaços, sendo assim, capazes de estruturar, de diferentes maneiras, a realidade exterior observável. Os apontamentos teóricos que justificam este estudo vinculam-se aos aportes fornecidos por geógrafos que, principalmente após o cultural turn processado na disciplina na década de 1970, possibilitaram o enriquecimento da abordagem cultural na geografia pela inclusão de abordagens semióticas, hermenêuticas e fenomenológicas na disciplina, aproximando-a teórica e metodologicamente das disciplinas humanísticas (SAHR, 2008).

Através desta "nova geografia cultural", compreende-se que a análise dos aspectos simbólicos, os sentimentos, o 'emocional-afetivo' dos indivíduos, constituem importantes fatores para a construção do espaço, assim como os dados objetivos, pois elaboram representações do mundo contemplado, abstrato ou concreto, atribuindo leituras ilustrativas permeadas de emoções e significados simbólicos, essenciais para a instituição da identidade dos indivíduos com o espaço (GOMES, 2007).

Compreende-se que não há espaços sem as práticas que lhes conferem sentido. 0 espaço incorpora os significados que lhe são atribuídos pelas relações sociais que o constroem e interpretam. Outrossim, o simbolismo analisado nestes estudos culturais não deve ser confundido apenas com as imposições do poder que visam sustentar uma estratégia de dominação, mas é também expressão da atividade dos indivíduos que buscam situar-se numa realidade exterior que a ultrapassa (MACIEL, 2005, 15-16).

A partir dos aportes teórico-metodológicos fornecidos por esta geografia de abordagem cultural, pode-se afirmar que nos produtos culturais em especial a música para este trabalho - encontram-se mais do que rimas e prosas, pois estes apresentam densos significados simbólicos inerentes a toda e qualquer ação humana de construção dos espaços.

As expressões artísticas tornam-se cada vez mais relevantes aos geógrafos a partir da referida renovação da geografia cultural, onde se descobriu que "a geografia não está apenas em toda par- te, mas também nas representações a respeito das paisagens, regiões, lugares e territórios" (CORRÊA; ROSENDHAL, 2009, p. 8). A música, assim como outras artes, como o cinema, a literatura e a pintura, revela-nos um imaginário onde são expressas visões de mundo e sentimentos diversos, e que, como criações sociais, podem ser vistas sob a ótica da espacialidade (Idem, p. 7-8).

Este imaginário, para CLAVAL (2008), é essencial à construção do espaço geográfico, pois permite compreender que as pessoas expõem as suas aspirações e feições pessoais aos espaços, construindo narrativas e símbolos no e do espaço para além do que seus sentidos lhes revelam. Esta construção de narrativas pelo imaginário geográfico, ocorre em relação direta com o espaço, produtor e produto dos simbolismos, onde os lugares concretos ligam-se à imaginação através de códigos e símbolos territoriais instituídos coletivamente (MACIEL, 2005).

Geógrafos desta renovada abordagem preocupam-se assim, em debater expressões culturais que tenham o espaço e o tempo como partes integrantes da trama (CORREAA; ROSENDAHL, 2007) e que favoreçam a análise dos aspectos simbólicos da paisagem (NETA, 2005), tomadas assim, como discursos, produtores da realidade, de sentidos e de significados (ALBUQUERQUE JR., 2001).

Compreende-se, então, que todo texto musical deve ser interpretado como um diálogo social em andamento, que ocorre em determinadas situações históricas e sociais, refletindo estes cenários (KONG, 2009, p. 141-142). Esta autora, aliás, aponta algumas razões para o estudo geográfico da música que merecem ser aqui apontadas. Ela considera que a música de um determinado lugar pode trazer imagens dele, servindo de fonte primária para se compreender o caráter e a identidade dos lugares. Além disto, a música também seria um importante meio para contar a experiência ambiental dos indivíduos (cotidianas ou fora do comum). Pode-se assim dizer que, "a música possui uma dualidade de estrutura: como o meio e como o resultado da experiência, ela pode produzir e reproduzir sistemas sociais (KONG, op. cit., p. 133-134).

Neste sentido, ao analisar os discursos engendrados pelo Movimento Mangue Beat para determinados espaços urbanos, pode-se compreender como movimentos culturais que eclodem em zonas periféricas (re) interpretam o mundo, participando da construção de novos espaços emblemáticos e reivindicando uma maior participação do papel popular no contexto político contemporâneo. Entende-se este movimento musical enquanto um ativismo social indutor de novos signos para a 
cidade, que conseguiu reivindicar, por meio da política - do discurso e da ação - a elucidação de problemas sociais e ambientais do Recife.

Nas re-interpretações e criações de novas imagens à cidade do Recife, o Mangue Beat conseguiu conferir novos signos aos mangues do Recife e uma reativação no debate sobre a organização espacial da "cidade anfíbia". Suas ideias favoreceram o desenvolvimento de um olhar crítico da cidade de Recife, ao construir imagens de si e da cidade, que podem ser visto nas suas músicas, na iconografia de seus álbuns e vídeos, assim como nas declarações de seus integrantes.

\section{O Movimento Musical Mangue Beat}

O Mangue Beat corresponde a uma cena cultural $^{4}$ que surgiu na década de 1990, na cidade de Recife, articulando elementos da "cultura tradicional" do Nordeste do Brasil (maracatu, ciranda, samba) com elementos globais ligados à cultura pop (rock, música eletrônica, rap, reggae). Caracterizado como um movimento que emergiu numa sociedade marcada por uma realidade espacial urbana de forte exclusão social, suas músicas e discursos caracterizam-se por uma visão crítica sobre o espaço que viviam, buscando mostrar suas próprias visões sobre a cidade.

Dentre as principais bandas que se destacaram nessa "nova onda" musical desenvolvida na Região Metropolitana do Recife, podem ser citadas diretamente, Chico Science \& Nação Zumbi e Mundo Livre S/A, e indiretamente, bandas como Eddie, Mestre Ambrósio, Devotos, Faces do Subúrbio, Sheik Tosado, dentre outras. Além do papel influente na música, o Mangue Beat teve importante influência sobre o cinema, sobre as artes plásticas, sobre a moda, contudo foi mais forte como um movimento musical.

Priorizando a análise das duas bandas principais deste movimento - e que assumiram diretamente a identidade de Mangue Beat - é importante destacarmos que os membros dos dois grupos são oriundos de diferentes estratos sociais da cidade do Recife. Conforme expõe Vargas (2007) o Mangue Beat ${ }^{5}$ formou-se pela junção de dois grupos de jovens. Um primeiro, formado por Fred Zero Quatro, Renato L., Xico Sá, H. D. Mabuse, e Hélder Aragão, todos de classe média, alguns universitários, interessados por música e que organizavam festas e discotecagens, influenciados pela filosofia do punk rock, que teria originado a Mundo Livre S/A. Um outro grupo, formado pela junção de Chico Science, Jorge du Peixe, Lúcio Maia e Dengue - membros do grupo musical Loustal, formado em 1989 e de membros do bloco carnavalesco de sambareggae Lamento Negro, desenvolvido pelo Centro Cultural Daruê Malungo, no bairro de Peixinhos ${ }^{6}$, subúrbio pobre de Olinda, que teria originado a Chico Science \& Nação Zumbi.

Para Teles (2000) o Mangue Beat corresponde a um movimento musical baseado numa democracia sócio-econômica, pois conseguiu mesclar pessoas de três diferentes estratos sociais em seus grupos: universitários de classe média (Zero Quatro, H.D. Mabuse, Renato L., Xico Sá, Carlos Freitas e Lúcio Maia); classe média baixa da periferia (Chico Science, Dengue, Du Peixe, Gilmar Bola 8) e alguns moradores dos "mocambos" ou "excluídos", do grupo Lamento Negro. Conforme este autor, a maior revolução promovida pelo Mangue Beat foi "quebrar um paradigma: em suas hostes, encontraram-se sem ranço, nem paternalismo, todos os estratos sociais" (TELES, op. cit, p. 274).

Fundamentados numa noção radical de hibridismo, que busca novas e múltiplas formas de influências, esta experiência musical procurou definir suas identidades através da negociação de informações culturais locais, regionais e globalizadas, negociando acordos entre o tradicional e o moderno, entre o nacional e o estrangeiro. Partem então, dos ritmos globalizados do rock, da black music, para voltar aos ritmos tradicionais pernambucanos que conheciam em sua infância, que para este autor, procede-se mais pela relação com o ritmo do que por um processo de reavaliação da música brasileira, baseado num posicionamento crítico, coletivo e independente para divulgação de

${ }^{4}$ Os "fundadores" desta cena cultural preferem caracterizá-la por dois termos: como "Cooperativa Cultural Mangue", pela atividade coletiva de organização de festas e apresentações, divisão de tarefas e custos; e "Cena Mangue Beat", por denotar um estado de acontecimento, sem deter a necessidade de uma proposta teórica fechada; Definido como "movimento Mangue Beat" pela mídia, inicialmente era chamado de "mangue bit" pelos grupos que o constituíam (o ecossistema mangue de um lado, e o bit, de binary digit, unidade de medida de informação dos sistemas eletrônicos, do outro), mas ficou comnhecido como "mangue beat" na mídia nacional, a partir de uma leitura equivocada da imprensa, que entendeu beat, do inglês "batida"(VARGAS, 2007).

${ }^{5}$ Grafia utilizada pelo autor.

${ }^{6}$ Outros autores afirmam que o grupo Lamento Negro era vinculado ao centro de apoio a comunidades carentes de Chão de Estrelas, localizado no bairro de Campina do Barreto, na Zona Norte do Recife. Sobre o assunto, ver Teles (2000) e a entrevista de Jorge du Peixe na revista da MTV número 69. 
seus trabalhos (TELES, op. cit).

A primeira vez que o termo "mangue" apareceu divulgado na imprensa para designar um estilo musical, foi numa matéria do Jornal do Comércio de 01/06/1991, intitulada de "Sons Negros no Espaço Óasis", para divulgar uma das festas desenvolvidas por seus membros (TELES, 2000). Esta aproximação entre os integrantes do movimento e os mangues de Recife talvez tenha se aprofundado quando, em 1992, Chico Science, Zero Quatro e Mabuse dividiram um apartamento na rua da Aurora, num prédio chamado Capibaribe, onde, era possível avistar das janelas do apartamento as áreas do porto, as pontes e rios da cidade.

No entanto, as intenções do movimento e a visão que seus integrantes tinham sobre a cidade do Recife só foram apresentadas oficialmente no primeiro manifesto do Mangue Beat, lançado em 1993, junto ao encarte do CD "Da Lama ao Caos" da banda Chico Science e Nação Zumbi. Intitulado como "Caranguejos com Cérebro" foi escrito por Fred Zero Quatro, um dos fundadores do movimento e vocalista da banda Mundo Livre S/A. Mesmo com a advertência de Jorge Du Peixe, em entrevista à revista da MTV em 2007, de que tal texto na verdade trata-se de um release de uma festa organizada pelos membros da banda, consideraremos neste texto o release "Caranguejos com Cérebro" como um verdadeiro "manifesto", pois este torna público os esforços dos integrantes do movimento na denuncia dos principais problemas da cidade, na tentativa de "salvar" a cidade do Recife.

\section{Manguetown - A Cidade}

A planície costeira onde a cidade do Recife foi fundada é cortada por seis rios. Após a expulsão dos holandeses, no século XVII, a (ex) cidade "maurícia" passou a crescer desordenadamente às custas do aterramento indiscriminado e da destruição dos seus manguezais. Em contrapartida, o desvairio irresistível de uma cínica noção de "progresso", que elevou a cidade ao posto de metrópole do Nordeste, não tardou a revelar sua fragilidade.

Bastaram pequenas mudanças nos "ventos" da história para que os primeiros sinais de esclerose econômica se manifestassem no início dos anos 60 . Nos últimos trinta anos a síndrome de estagnação, aliada à permanência do mito da "metrópole", só tem levado ao agravamento acelerado do quadro de miséria e caos urbano.

O Recife detém hoje o maior índice de desemprego do país. Mais da metade dos seus habitantes moram em favelas e alagados. Segundo um instituto de estudos populacionais de Washington, é hoje a quarta pior cidade do mundo para se viver. (CHICO SCIENCE \& NAÇÃO ZUMBI, 1994).

Apropriando-se do sugerido por Vargas (2007), acreditamos que o argumento central deste primeiro manifesto corresponde a uma tentativa de relacionar a riqueza e diversidade ecológica dos ambientes de manguezais à cultura recifense - fornecendo um poder metafórico aos manguezais e estuários da cidade, atribuindo através dessas representações, um poder de ligação entre a cultura e as identidades da cidade.

A partir de uma "brincadeira levada a sério" (SOUZA, 2000), o Mangue Beat provocou na sociedade recifense uma necessidade de se pensar sobre os seus complexos problemas sociais, atitude esta que, antes de mais nada, corresponde aos frutos da experiência da juventude urbana recifense, que através das suas músicas, tematizaram os problemas que experimentavam na condição de jovens saidos dos seguimentos de menor poder aquisitivo, e que conseguiram se projetar, colocando-se no centro da cena cultural de sua cidade e de seu país (SOUZA, 2000, p. 5).

Compreendemos assim, que o Mangue Beat correspondeu a um fenômeno cultural resultante da confluência de diversas experiências sociais e estéticas, que buscavam denunciar a situação de desigualdade encontrada na sociedade recifense. Buscavam demonstrar a relação entre a metrópole e o mangue, entre seus habitantes quase distintos, lançando os problemas da bela e perversa Recife, mostrando o olhar da periferia sobre a metrópole do Nordeste, com sua miséria acumulada, do qual apenas usufruíam parcialmente, ou para alguns nem isso. Enquanto muitos viam a cidade do Recife buscando contemplar suas belezas, suas histórias e seus atrativos turísticos, o Mangue Beat buscava explicitar a realidade opressora da cidade. Procuravam mostrar a cidade espacialmente fragmentada, presa no mito da metrópole, repleta de problemáticas urbanas, que cada vez mais levavam ao agravamento do quadro de miséria e caos urbano.

Nem telúrico, nem neomiserável, em um país neo-social. Produção cultural urbana, experimental, crítica, avessa aos encantos da 'indústria cultural', produzida por grupos marginais, cheia de sonhos e imagens do desejo, mas profundamente refrataria às formas de sociabilidade do Brasil institucional. Formas culturais heterogêneas, disformes, caóticas, mas respresentativas do 
processo de exclusão social existente no país (ZAIDAN FILHO, 2004, p. 3738).

Para Leite (2002) este movimento musical promoveu a recuperação do discurso sonoro da cidade, a partir da exaltação das contradições da cidade sem a utilização de uma apologia ufanista da cultura pernambucana, cantando a miséria da periferia e contribuindo para uma nova reapropriação da cultura popular.

Em outra importante contribuição ao estudo do Mangue Beat, Neta (2005) destaca ainda, que a construção das identidades do Mangue Beat desenvolveram-se diretamente relacionadas com o espaço, onde as metáforas espaciais criadas objetivavam atribuir sentidos ao processo de identificação, através de respostas não-etnocêntricas às questões periféricas da cidade do Recife, com grande engajamento político. Sobre a atitude política deste movimento, Hermano Viana certa vez falou que

[O Mangue Beat] Não é político no sentido parlamentar do termo: o buraco aqui está mais embaixo, mais na Lama. A atividade Mangue no Recife foi política sem aliança com os políticos. A sua lição mais básica foi absolutamente clara: se o mundo está ruim, mudemos o mundo. Se a cidade do Recife está culturalmente estagnada, implantemos na cidade sem a ajuda ou o mecenato de ninguém um estado caótico de agitação artística. Não adianta ficar sentado no bar (cadê Roger?) reclamando da vida, da distância de Londres ou de Nova Iorque. Basta fazer alguma coisa, qualquer coisa boa. Basta confiar na própria criatividade (VIANA apud VARGAS, 2007, p. 111).

Convém destacar então, que a interpretação do movimento Mangue Beat neste trabalho é baseado na idéia que este se desenvolveu em relação direta com o espaço da cidade do Recife, criando novos signos para a cidade, e reivindicando, por meio da política - do discurso e da ação - a elucidação de problemas sociais e ambientais do Recife, lançando novos debates sobre os ambientes do rio Capibaribe.

\section{O Mangue Beat e os Novos Olhares sobre o Recife}

Convém salientar, antes de continuarmos esta discussão, que interpretamos o Mangue Beat como um dos inúmeros discursos sobre o Recife que acrescentaram/atualizaram sentidos às metonímias paisagísticas locais, assim como criando novas metáforas sobre a cidade. Sem querer atribuir ao Mangue Beat uma atitude heróica única na cidade, compreendemos que outros discursos, autores, cientistas já decantaram a beleza, os problemas e a dinâmica destas paisagens antes dos mangueboys e manguegirls. Além do mais, dependendo das respostas que buscarmos, veremos que o Capibaribe e seus espaços alagadiços cantados nesta cena musical talvez nunca tenha deixado de ter uma imagem positiva - pela sua beleza e historicidade - ou uma imagem negativa - pela sua ameaça e/ou poluição. Numa cidade tão plural, torna-se extremamente difícil e perigoso atribuirmos uma interpretação a estas paisagens como uma verdade apriorística. Assim, pensamos deixar claro que a escolha pelo Mangue Beat baseou-se, além da sua contemporaneidade, na delimitação de um corpus metodológico ao trabalho, sem tentativas de reificar as ações deste movimento .

Retomando, na análise da iconografia produzida por seus integrantes, destacamos um conjunto de assuntos centrais abordados de interesse ao estudo geográfico em questão. A saber: a articulação de discursos sociais através da música, revelando as realidades sociais da cidade; a reativação de debates desenvolvidos pelo geógrafo Josué de Castro, tais como a realidade dos mocambos, e a situação de abandono social que vivem seus homens-caranguejos; sobre as relações interescalas observadas nas cidades emersas nas novas dinâmicas da globalização high-tech; a tematização do mangue enquanto caráter identitário da cidade, lançando a ideia da Manguetown, da cidadeestuário.

Convém destacar ainda, a partir do exposto por algumas contribuições teóricas, que este movimento artístico tece visões sobre a cidade do Recife a partir da imagem de uma cidade cindida pela concentração de renda, representando o espaço urbano a partir da ênfase de alguns aspectos mais centrais, tais como a violência, a desigualdade de renda e a cidade como uma heterogeneidade social (NETA, 2007).

A (re)construção destas imagens e sentidos pelo Mangue Beat corresponde a um fator crucial para entendermos a realidade da cidade do Recife, pois o imaginário mediado por tais tipos de expressões culturais interferem em fenômenos geográficos concretos, atribuindo valor a dados espaços, podendo ser estudados como verdadeiros

${ }^{7}$ Neste ponto, agradecemos as valiosas observações feitas pelo Prof. Jan Bitoun, assim como suas sugestões bibliográficas. 
sistemas simbólicos que articulam debates sociais. Estas novas imagens evidenciam os interesses do Mangue Beat para com o mundo, apresentando uma consistência histórica e geográfica profunda, pois exprimem as percepções e comportamentos dos que a mobilizam e re-interpretam em novas metáforas. Além disso, alguns dos integrantes desta "cena" recentemente têm tido ação destacada em alguns órgãos governamentais, casos de Renato L. (Secretário de Cultura da PCR); Roger de Renor (diretor-presidente da TV Pernambuco e articulador da ativação da rádio pública Frei Caneca); Fred Zero Quatro (ex-assessor da Secretaria de Cultura da Prefeitura do Recife).

É neste sentido, que corroboramos com Kong (2009, p. 133-134; 153-154) quando esta afirma que a música, enquanto meio e resultado das experiências individuais e/ou coletivas, é capaz de produzir/reproduzir sistemas sociais, apresentando um papel de construção social de identidades, onde estas expressões culturais possibilitam uma comunicação capaz de produzir, manter, transformar, negociar e confrontar significados. Acredita-se então que, os discursos lançados pelo Mangue Beat apresentam um potencial de revelar as realidades sociais da cidade pois estes desenvolveram lutas e estratégias de ação social que buscavam um maior respeito e inserção dos espaços e sujeitos periféricos.

E tal reinvidicação é feita não através de um olhar distante, de quem vivencia os problemas da cidade num olhar vertical, tal como visto pelas imagens vendidas da "Veneza Brasileira", e sim do olhar de quem vivencia de perto as mazelas sociais da cidade, de quem é um habitante da tematizada Manguetown, a "cidade complexo, do caos portuário" ou daqueles que vêem de perto a ausência de alternativas dos "homens que em tudo mimetizam os caranguejos" (CASTRO, 2010), degradados física e civicamente. Visualiza-se neste movimento cultural o "olhar morfológico" espontâneo e crítico do qual Sauer (2000) faz referência. Aquele olhar que procura observar o visível, mas também registrar todos os detalhes, questionar, confirmar e apontar novos fatos, objetos e sentidos da paisagem. Um olhar que provoca mudanças de percepções dos que o acompanham.

Um dos temas centrais das músicas das bandas que faziam parte do Mangue Beat, corresponde a figura do homem periférico, em especial, o que mora nos mangues do Recife. Em suas interpretações, exploram a imagem do homem suburbano, completamente pobre e miserável, excluído social e espacialmente da cidade do Recife, e que luta para sobreviver nos manguezais e também nos morros do Recife. Em tal ponto, aproximam sua interpretação das de Josué de Castro, em seu romance "Homens e Caranguejos".

São as "impressionantes esculturas de lama" cantada pela Nação Zumbi, reflexo dos "cavaleiros da miséria com suas estranhas armaduras de barro", do romance Homens e Caranguejos, de Josué de Castro. Desenvolvem também a idéia do Homem-Gabirú. Ambos buscam dar forma a indignação que sentiam com a tragédia cotidiana da miséria humana vivenciada na cidade do Recife.

\section{Rios, Pontes \& Overdrives \\ (Chico Science e Fred Zero Quatro)}

Porque no rio tem pato comendo lama

Rios, pontes e overdrives

Impressionantes esculturas de lama

Mangue, mangue, mangue, mangue, mangue, mangue, mangue

E a lama come mocambo e no mocambo tem molambo

E o molambo já voou, caiu lá no calçamento bem no sol do meio-dia

O carro passou por cima e o molambo ficou lá Molambo eu, molambo tu, molambo eu, molambo tu.

\section{Da Lama ao Caos (Chico Science)}

Posso sair daqui para me organizar Posso sair daqui para desorganizar Da lama ao caos. Do caos à lama

Um homem roubado nunca se engana 0 sol queimou, queimou a lama do rio

Eu vi um chié andando devagar

Vi um aratu pra lá e pra cá

Vi um caranguejo andando pro sul

Saiu do mangue, virou gabiru

Oh Josué, eu nunca vi tamanha desgraça

Quanto mais miséria tem, mais urubu ameça.

Ao desenvolver a continuação da metáfora iniciada por Josué de Castro dos "Homenscaranguejos" (CASTRO, 2010), transformando estes nos "Caranguejos-com-cérebro", a cena Mangue consegue "reumanizar aqueles habitantes da cidade que haviam sido desumanizados", esquecidos pelo modelo econômico de desenvolvimento excludente, caranguejos estes que assinam o manifesto do movimento (MELO FILHO, 2003, p. 518). Tais metáforas presentes nas obras do Mangue Beat e do geógrafo Josué de Castro procuram demonstrar uma inquietação frente a miséria presente na sociedade, colocando a fome, a miséria e a exclusão social diretamente relacionadas com as relações sócio-políticas. 
A própria utilização do caranguejo nestas representações, a partir da elaboração destes "personagens kafkianos" assume uma conotação sócioeconômica, pois esta adquire o poder de representar as populações ribeirinhas, de representar o homem explorado pelo sistema, a partir da metaforização "do 'ser' que cava a lama para dos mangues retirar os nutrientes necessários; como um "ser" que participa ativamente das trocas orgânicas que se dão no manguezal" (VARGAS, 2007, p. 71-72). Assim, além da imagem opressiva destas tematizações, estas adquirem também, uma imagem libertadora, na medida que a atitude de cavar o chão do mangue apresenta a capacidade de oxigenar o pântanos do Recife, podendo assim, reanimar a vida da cidade.

Conforme já relatado acima, as músicas do Mangue Beat relacionam-se com algumas questões expostas por Josué de Castro. Em depoimento disponível no Memorial Chico Science, o jornalista Renato L., um dos principais nomes do movimento admite que os livros do geográfo pernambucano constituíram-se enquanto bons companheiros dos integrantes do movimento, onde "a Geografia da Fome, de Josué de Castro, dividiu sem ciúmes a cabeceira da cama com os clássicos da ficçãocientífica $^{8 \prime \prime}$ e assim como o autor, reconhecem que, a problemática social recifense encontra-se relacionada com questões político-econômicas além das questões locais, como observado no trecho abaixo:

\section{A Cidade \\ (Chico Science)}

A cidade se encontra prostituída

Por aqueles que a usaram em busca de saída Ilusora de pessoas de outros lugares

A cidade e sua fama vai além dos mares No meio da esperteza internacional

A cidade até que não está tão mal

E a situação sempre mais ou menos

Sempre uns com mais e outros com menos

A cidade não pára, a cidade só cresce

O de cima sobe e o de baixo desce.

Tal visão da cidade onde "o de cima sobe e o de baixo desce" assemelha-se fortemente à visão de que o menino João Paulo, do romance "Homens e Caranguejos", presenciou quando subiu na torre da Igreja de Afogados:

João Paulo subiu à torre da igreja e, do alto, naquela hora em que o sol se punha, viu a cidade inteira vestida de roxo. De um lado, as casas crescendo cada vez mais com a distância, até virarem arranha-céus no centro da cidade. As torres das igrejas também crescendo cada vez mais, até alcançarem as alturas imensas das torres das igrejas do bairro do Recife. Do outro lado, as casas diminuindo de altura, ficando cada vez mais baixas com a distância, virando mocambo e latadas, até desaparecerem de todo dentro da lama do mangue. [...] João Paulo sentia-se como se estivesse no lombo de uma montanha que fosse um divisor de águas, de onde corriam, para um lado, os rios da fortuna e, para o outro lado, os rios da miséria (CASTRO, 2010, p. 70, grifo meu).

Queremos assim dizer que nesta cidade cindida, onde dois rios sociais parecem cada vez mais se separar, não é somente a visão incorfomada e angustiante dos mangueboys que se assemelha à de João Paulo. Na verdade, pensamos aqui como que a visão de João Paulo fosse a própria visão destes mangueboys. Assim como o personagem do romance de Josué de Castro, percebemos no Mangue Beat uma vontade de reagir à depressão, de libertar seus espaços de vivência das garras das paisagens negras dos mangues do Capibaribe, com suas folhas viscosas e sua lama pegajosa.

Assim, a visão de Chico Science e dos demais mangueboys aproxima-se da defendida por Josué de Castro, correspondente à visão retórica dos mangues, através do resgate de vivências da infância, atribuindo um tom agressivo a paisagem urbana "formal", e um tom romântico a paisagem dos mocambos, evidenciando assim, as paisagens dominantes e excluídas da cidade (NETA, 2007).

Tematizam então, os mangues do Recife como uma periferia entregue à miséria e ao descaso do poder público. Tal periferia não é, no entanto, tematizada como um local conformado com a miséria, acostumado a sofrer calado e satisfeito. Mas sim uma periferia que coloca o mangue como insurreição. Os mocambos e seus molambos como agentes ativos na dinâmica urbana do Recife. Com idéias próprias, questionadores e inconformados. E acima de tudo cidadãos esquecidos pelo sistema econômico avassalador. Esquecidos e não vencidos. Pois da lama pode vir o caos. Da lama da miséria pode vir a coragem pra se enfrentar os urubus. Percebemos em ambos, o desejo de evadir desta "paisagem humana parada e monótona. Desejo

${ }^{8}$ Depoimento de Renato L. intitulado “Dez anos sem o cientista dos ritmos", disponível no site do Memorial Chico Science: http://memorialchicoscience.com/. Acesso em: 25 jan. 2010. 
imperioso de sair de tudo. De sair de dentro de si mesmo. De sair do círculo fechado da família. Do ciclo do caranguejo. Da cidade do Recife" (CASTRO, 2010, p. 42). Recife, cidade onde a lama corresponde a uma metaforização da estratificação social, mas também adquire o perfil de uma possível insurreição.

\section{Antene-se \\ (Chico Science)}

É só uma cabeça equilibrada em cima do corpo

Escutando o som das vitrolas, que vem dos mocambos

Entulhados a beira do Capibaribe

Na quarta pior cidade do mundo

Recife, cidade do mangue

Incrustada na lama dos manguezais

Onde estão os homens carangueijos

Minha corda costuma sair de andada

No meio da rua em cima das pontes [...]

Recife, cidade do mangue

Onde a lama é a irresureição

Os mocambos tematizados pelo Mangue Beat, em especial na banda Chico Science \& Nação Zumbi promovem a retomada do termo já em desuso "mocambo", resgatando assim, o debate das raízes sociais, culturais e econômicas da cidade, promovendo a retomada do debate sobre a formação sócio-econômica da cidade e do conseqüente agravamento da concentração de renda característica da cidade (NETA, 2007).

Encarando este tipo de habitação popular enquanto um lócus de reprodução social de uma população miserável, assim como o fez Josué de Castro, interpretam o mocambo como um símbolo da miséria e desigualdade social da cidade, como um fenômeno a ser superado, mas também, como um lugar de referência, de vínculos simbólicos do seu morador, como se a identificação da cidade com o mangue correspondesse ao próprio processo de identificação dos mocambeiros com o local de moradia (idem, ibidem), tal qual o amor dos homens-caranguejos pela risoflora (em referência à Risophora mangle).

\section{Risoflora (Chico Science)}

Oh Risoflora!

Vou ficar de andada até te achar Prometo meu amor vou me regenerar Oh Risoflora!

Não vou dar mais bobeira dentro de um caritó

Oh Risoflora, não me deixe só

Eu sou um carangueijo e quero gostar
Enquanto estou um pouco mais junto eu quero te amar

Ao compreender o mangue como um lugar dos excluídos sociais, o Mangue Beat coloca como o cerne desta problemática social do Recife as relações sociais e econômicas deste sistema, colocando-os diretamente responsáveis por produzir e manter o fenômeno da pobreza urbana. 0 uso dessas metáforas coloca a cidade como palco e espelho da luta pela sobrevivência, que expressa a luta dos moradores das periferias recifense, da cidade dos manguezais - agora a Manguetown - que sofrem com as espacializações de desigualdades fixadas no cerne da sociedade. Expõem uma realidade espacial da cidade do Recife que difere das apresentadas em cartões postais (a Veneza brasileira, a Veneza americana).

Referindo-se a cidade do Recife através da fedentina exalada pelos rios e manguezais, Chico Science parece fazer referência à podridão do jogo social da cidade, das desigualdades sociais espacialmente localizadas no Recife (NETA, 2007). Os rios e mangues talvez não sejam os maiores culpados pela fedentina habitual da cidade. Estes, pelo contrário, ao costurar as mazelas sociais aos centros de ambição num único tecido urbano, tem o poder de aproximar os espaços estratificados da cidade, seja pelas pontes físicas, seja pelos odores exalados destes corpos líquidos. Convém lembrar que para Claval (1999, p. 84) a lembrança mais tenaz que guardamos dos lugares está, frequentemente relacionada aos cheiros e odores dos quais estes são portadores.

Mesmo ao trabalhar uma conexão entre as cenas culturais observadas na cidade do Recife com os fenômenos culturais difundidos pelas industrias culturais de caráter global, possibilitaram o desenvolvimento de uma luta para impedir que a economização da vida social imposta pela cultura de massas se expandisse na cidade através da força da propaganda e de seus valores globais. Como exposto por Angela Prysthon (2004), o Mangue Beat, ao emergir da "periferia da periferia" revela-se como um dos diálogos mais radicais entre tradição e modernidade, entre centro e periferia na música popular dos anos 1990. E tal diálogo fica evidente na interpretação da imagem símbolo do movimento, a "parabólica enfiada na lama", uma simples tradução visual da combinação destas dualidades proposta pelo movimento, representação simbólica da relação estabelecida entre a natureza e a cultura urbana do Recife, tão cara a sua formação histórica, história esta corporificada na elaboração da metáfora formada na imagem de uma ante- 
na tecnológica afundando-se num mar de lama (VARGAS, 2007).

Ao encenarem em suas expressões musicais as diferenças observadas entre o local (em específico o cotidiano de uma cidade localizada num país subdesenvolvido) e o global (as constantes relações estabelecidas com a tecnologia e as imagens metropolitanas), elaboram um redirecionamento do papel do "popular" no contexto contemporâneo. Seguem à risca a receita que coloca a autoconsciência como principal saída (cosmopolita) para a afirmação periférica (PRYSTHON, 2004, p. 43-45).

Estes, narram a cidade de forma avessa, ou pelo menos incitam uma leitura às avessas de alguns de seus principais geossímbolos (os manguezais, rios, alagadiços, etc). Nos seus aspectos mais familiares, nos seus monumentos e espaços públicos mais simbólicos, (rios, pontes, mangues), buscam expor aquilo que já não é perceptível pela sociedade. Tais espaços são por eles contemplados, mas principalmente, contestados em suas problemáticas. Nos espaços onde as pessoas não mais enxergavam suas realidades sociais desastrosas, o movimento enxergava e tentava torná-los perceptíveis para o restante da população. Marcelo Pereira, editor do Caderno C do Jornal do Comércio, um importante caderno jornalístico de divulgação do Mangue Beat, resume da seguinte forma este olhar às avessas dos mangueboys:

Descer o Capibaribe com olhos de turista ou navegante é, para muitos recifenses ou recifencizados [...] uma descoberta fascinante e bela, ao mesmo tempo cruel, como a poesia que se escreve, com tintas desta mesma água e lama. A realidade cotidiana das margens ribeirinhas do Planeta Mangue denunciam um outro Recife, mais cru, ingrato, abandonado à sorte. São as entranhas de uma cidade cartão postal, entrecortada de belezas naturais e outras moldadas pela arquitetura criativa dos recifenses, mas nem sempre definitiva, e alimentada pela alegria e hospitalidade decantada dos pernambucanos. Há nessas entranhas uma poética do avesso, extraída da lama e da alma - uma dentro e fora da outra, ser e palavra - dos homenscaranguejos e mangueboys (Marcelo Pereira, depoimento ao Memorial Chico Science ${ }^{9}$ ).
Ao promoverem tais críticas da/sobre a cidade, as suas músicas conseguiram estimular transformações nas identidades sócio-espaciais da cidade, a partir do momento que desenvolveram um conjunto de metáforas que passou a conceituar os manguezais e ambientes estuarinos como o coração da cidade, como o único espaço capaz de impedir que a cidade do Recife afundasse numa "depressão crônica que paraliza os cidadãos".

Tais metáforas, incorporadas pelas diferentes classes sociais da cidade, apresentaram e ainda hoje são importantes discursos com potencial de agrupar diferentes identidades em torno dos espaços mais símbolicos da cidade: o estuário dos rios Capibaribe e Beberibe no centro históricogeográfico da cidade.

Analisando as contribuições de Michel Roux e sua geografia do imaginário, Caio Maciel considera que os homens se reportam nostalgicamente a alguns espaços míticos, a partir da eleição de algumas imagens e metáforas que, de certa forma, corresponde a uma maneira de "reencontrar o equilíbrio telúrico que a modernidade técnica e os valores do progresso romperam" (MACIEL, 2012, p. 79). Assim, convém destacar que representações como estas desenvolvidas pelo Mangue Beat teriam como papel uma "função existencial da individuação", que permite aos indivíduos a busca por se diferenciar dos outros, e, ao mesmo tempo, se integrar ao coletivo.

\section{Considerações Finais}

Ao interpretarmos o Mangue Beat como um movimento inspirado na geografia da cidade do Recife, que buscava encenar sobre as condições sociais de seus moradores e as problemáticas da cidade, conclui-se que o movimento incentivou nestas ações a valorização dos imaginários geográficos da cidade, jogando imagens do cotidiano na música. Possibilitaram um questionamento das imagens-símbolos da cidade, buscando demonstrar as desigualdades do Recife, suas problemáticas urbanas, explicitando a realidade da cidade, por muitos já esquecida ou abafada.

0 movimento possibilitou grandes mudanças na sociedade recifense. Mudanças na forma do recifense ver sua cidade, na forma como ele questiona seus problemas e percebe o seu espaço urbano, e até na forma como se vêem enquanto cidadãos do mundo, enquanto membros de uma sociedade global. Colocou a cultura popular no debate promovi-

${ }^{9}$ Depoimento intitulado "Mangueletter: poética, agridoce, colagem (clonagem) popconcreta e antenada para o Planeta Mangue, escrita nos 459 anos da própria Manguecéia tresloucada", disponível na homepage do Mmorial Chico Science: http://memorialchicoscience.com/. 
do até então por estudiosos e acima de tudo, demonstrando a efervescência cultural e política que provém dos espaços periféricos da cidade.

A aproximação teórica com a geografia cultural neste estudo tentou apontar os componentes políticos que as expressões artísticas suscitam, demonstrando que estas, além de serem desenvolvidas em relação direta aos processos de apropriação espacial, correspondem igualmente a discursos que encontram-se carregados de simbolismos, sendo assim co-fundadores das paisagens, e igualmente elementos-chave da coesão política da espacialidade pública.

Acredita-se assim que se faz mais do que necessário revisitar a cidade na perspectiva da subjetividade de suas paisagens (tanto nos seus elementos construídos ou nos elementos físiconaturais), pois além de interpretarmos como as pessoas vêem seus espaços vivenciados estaríamos desvendando as ordens de significados e códigos de referência espacial que estruturam as dinâmicas sociais.

Convém lembrar que a crítica da cidade reelaborada pela cena mangue a partir de contribuições diversas, ressaltando-se a figura de Josué de Castro, pretendeu ser muito mais abrangente e integrativa (o estuário ligando todos os pontos e todas as frações de classe da Manguetown, em ebulição e potencialmente em revolta) do que as propostas recentes de transformações urbanas desenvolvidas pela Prefeitura do Recife.

\section{Referências}

ALBUQUERQUE JR., D. M. A Invenção do Nordeste e outras artes. $2^{\circ}$ edição. São Paulo: Cortez, 2001.

CASTRO, J. de. Homens e Caranguejos. 4ํe. ed. Rio de Janeiro: Civilização Brasileira, 2010.

CLAVAL, P. A Geografia Cultural: o estado da arte. In: CORRÊA, R. L.; ROSENDAHL, Z. (Org.). Manifestações da Cultura no Espaço. Rio de Janeiro: EdUERJ, 1999, p. 59-97.

Uma, ou algumas, abordagem(ns) cultural(is) na Geografia Humana? In: SERPA, A. (Org.). Espaços Culturais: vivências, imaginações e representações. Salvador: Edufba, 2008, p. 13-29.

Cinema, Música e Espaço - Uma introdução. In: CORRÊA, R. L.; ROSENDAHL, Z. (Org.). Cinema, Música e Espaço. Rio de Janeiro: EdUERJ, 2009, p. 7-13.
GOMES, E. T. A. Recortes de Paisagem na Cidade do Recife: uma abordagem geográfica. Recife: Massangana, 2007.

KONG, L. Música Popular nas Análises Geográficas. In: CORRÊA, R. L.; ROSENDAHL, Z. (Org.). Cinema, Música e Espaço. Rio de Janeiro: EdUERJ, 2009, p. 129-175.

LEITE, R. P. de S. Contra-usos e espaço público: notas sobre a construção social dos lugares na Manguetown. Revista Brasileira de Ciências Sociais, São Paulo, vol. 17, número 49, 2002, p. 115-134. Disponível em: <http://www.scielo.br /pdf/rbcsoc/v17n49/a08v1749.pdf>. Acesso em: 22 jan. 2010.

MACIEL, C. A. A. Espaços Públicos e geosimbolismos na "cidade estuário": rios pontes e paisagens do Recife. Revista de Geografia da UFPE, Recife, v. 22, no1, JAN/JUL, 2005, p. 10-18.

A Geografia Política da Paisagem: imagens, narrativas e sensibilidades culturais em disputa no espaço público recifense. 2010. In: MACIEL, C. A. A.; GONÇALVES, C. U.; PEREIRA, M. C. de B. (Org.). Abordagens Geográficas do Urbano e do Agrário. Recife: EdUFPE, 2012, p. 26-41. (No prelo)

MELO FILHO, D. A. Mangue, Homens e Caranguejos em Josué de Castro: significados e ressonâncias. História, Ciências, Saúde - Manguinhos, Rio de Janeiro, vol. 10(2), maio-ago 2003, p. 505-524. Disponível em: < http: / / www.scielo.br /pdf/hcsm/v10n2/17748.pdf>. Acesso em: 15 fev. 2009.

NETA, M. A. V. Geografia e Literatura: decifrando a paisagem dos mocambos do Recife. 2005, 116 f. Dissertação (Mestrado em Geografia) - Universidade Federal do Rio de Janeiro, Rio de Janeiro, 2005.

A dimensão espacial do movimento mangue e a construção de uma identidade territorial: visões sobre o urbano e os locais de moradia. Terr@ Plural, Ponta Grossa, 1(2), ago.-dez., 2007, p. 29-40. Disponível em: < http://www.revistas2. uepg.br/index.php/tp/article/viewFile/1150/86 2>. Acesso em: 25 set. 2010.

PRYSTHON, A. Diferença, pop e transformações cosmopolitas no Recife a partir do Movimento Mangue. Revista Fronteira - estudos midiáticos, São Leopoldo, v. VI, n. 1, 2004, jan/jun, p. 33-46. Dispo- 
nível em: <http://www.unisinos.br/publicacoes_ cientificas/images/stories/pdfs_fronteiras /edicoes_anteriores/07_fronteiras_volvi_n1_artigo03.pdf>. Acesso em: 01 fev. 2010.CORRÊA, R. L.; ROSENDAHL, Z. Literatura, Música e Espaço - Uma introdução. In: CORRÊA, R. L.; ROSENDAHL, Z. (Org.). Literatura, Música e Espaço. Rio de Janeiro: EdUERJ, 2007, p. 7-16.

SAHR, W. D. G. J. Ação e EspaçoMUNDOS - a concretização de espacialidades na Geografia Cultural. In: SERPA, A. (Org.). Espaços Culturais: vivências, imaginações e representações. Salvador: Edufba, 2008, p. 33-57.

SAUER, C. O. Geografia Cultural. In: CORRÊA, R. L.; ROSENDAHL, Z. (Org.). Geografia Cultural: um Século(1). Rio de Janeiro: EdUERJ, 2000, p. 99110.

SOUZA, C. M. de. Da Lama ao caos: Diversidade, diferença e identidade cultural na cena Mangue do Recife. En publicacion: Informe final del concurso - Culturas e identidades en América Latina y el Caribe. Programa Regional de Becas, CLACSO, Buenos Aires, 2001. Disponível em: <http:// bibliotecavirtual.clacso.org.ar/ar/libros/ becas/2000/morais.pdf>. Acesso em: 09 mar. 2009.
TELES, J. Do Frevo ao Manguebeat. São Paulo: Editora 34, 2000.

VARGAS, H. Hibridismos Musicais de Chico Science \& Nação Zumbi. São Paulo: Ateliê Editorial, 2007.

ZAIDAN FILHO, M. Pernambuco falando para o mundo. Recife: Livro Rápido, 2004.

\section{Discografia}

Chico Science \& Nação Zumbi. Da Lama ao Caos. São Paulo: Chaos/Sony Music, 1994.1 CD.

Afrociberdelia. São Paulo: Chaos/Sony Music, 1996.1 CD.

Mundo Livre S/A. Samba Esquema Noise. São Paulo: Banguela Records, 1994.1 CD.

Guentando a Ôia. São Paulo:

Excelente Discos, 1996.1CD. Carnaval na Obra. São Paulo:

Excelente Discos, 1998. 1 CD. 


\title{
Imaginary bridges over the manguetown's sky: the mangue beat and the new perspectives about the Recife
}

\begin{abstract}
The main issue of this paper is to analyze the Mangue Beat movement, trying to understand how discourses of cultural scene contributed to the reconstruction and/or reshaping the landscape of the city of Recife, through the creation of new signs for the town and its public spaces. The project was developed through research the iconography of the Mangue Beat cultural production, coupled with review of literature on the problematic socio-spatial of Recife and observations techniques in the urban city. Search will be pointing in the results that criticism of the city prepared by the scene Mangue from various contributions, intended to be more comprehensive and integrative (the estuary connecting all points and all strata of the Manguetown, boiling and potentially revolt) than the proposed urban transformations developed by the city, after the critical debate promoted by this movement.
\end{abstract}

Keywords: Recife; Mangue Beat; River Capibaribe; Landscape

\section{Puentes imaginarias en el marco del cielo de la manguetown: el mangue beat y los nuevas miradas en el Recife}

\begin{abstract}
Resumen: El tema principal de este trabajo es analizar el movimiento Mangue Beat, tratando de entender cómo los discursos de la escena cultural ha contribuido a la reconstrucción y/o transformacion el panorama de la ciudad de Recife, a través de la creación de nuevos signos para la ciudad y sus espacios públicos. El proyecto fue desarrollado a través de la investigación sobre la iconografía de la producción cultural de Mangue Beat, junto con la revisión de la literatura sobre la problemática socio-espaciales de Recife y observaciones técnicas en la espacio urbana. La búsqueda se apunta en los resultados que la crítica de la ciudad preparado por la escena Mangue atraves de contribuciones varias, destinados a ser más amplio e integrador (el estuario de conectar todos los puntos y todos los estratos de la Manguetown, hervir y, potencialmente, rebelión) que las transformaciones urbanas propuestas desarrolladas por la ciudad, después de que el debate crítico promovida por este movimiento.
\end{abstract}

Palabras clabe: Recife. Mangue Beat. Río Capibaribe. Paisajes. 